\title{
Ovarian Surface Papilloma
}

National Cancer Institute

\section{Source}

National Cancer Institute. Ovarian Surface Papilloma. NCI Thesaurus. Code C7279.

A benign serous neoplasm characterized by the presence of papillary proliferations on the surface of the ovary. 